Leadership Preferences of Mentally Tough Athletes

Keywords: Challenge, commitment, control, confidence, leadership behaviours. 
Abstract

This study examined the leadership preferences of mentally tough athletes. A sample of 103 athletes $(M$ age $=22.06$ years, $S D=4.37)$ participated and ranged from club / university level to county standard in a variety of team sports. Participants completed the Leadership Scale for Sport - Preference Version (Chelladurai \& Saleh, 1978) to measure preferred leadership, and the MTQ48 (Clough et al., 2002) to measure mental toughness. Mental toughness was predicted to be significantly and positively related to a preference for training and instructive behaviours, and negatively related to a preference for social support. Linear regression analysis and Pearson correlations were used to analyse the data. Consistent with theoretical predictions, mental toughness was found to be significantly related to a preference for training and instructive behaviours $(r=0.40, P<$ .01). Results of linear regression analysis revealed the MTQ48 subscales of commitment and challenge were significant predictors of preference for training and instructive behaviours. Total mental toughness was not found to be significantly related to preference for social support, democratic behaviours, autocratic behaviours or positive feedback $(P>.05)$. This suggests that coaches working with mentally tough athletes should consider emphasising training and instructive behaviours if they wish to attain congruence between actual and preferred leadership behaviours. Greater research into the influence of personality upon athlete leadership preferences is encouraged. 
Introduction

Effective leadership in sport appears to be determined by interactions between multiple factors such as leader behaviour, athlete characteristics, and situational factors (Chelladurai, 2001; Horn, 2008). Riemer (2007) suggests that leadership is a complex behavioural process that involves dealing with group dynamics, interpersonal communications, and achievement or moving towards goals. Leadership behaviours appear to influence both performance and satisfaction of teams and athletes. Barrow (1977, p.232) defined leadership as, 'the behavioural process of influencing individuals and groups towards set goals.' In sport settings, leadership is primarily provided by coaching staff and represents coaching behaviours.

The multidimensional model of leadership (Chelladurai, 1978, 1990, 1993, 2001) is a theoretical framework that is based upon an interactional view of leadership in sport. Central to this model is the hypothesis that team performance and satisfaction are primarily determined by the extent to which a coach's actual behaviour matches the preferences of athletes (within situational constraints). When congruence is achieved (i.e. when a coach's actual behaviour matches the athletes preferred behaviours and the behaviours required in a given situation) then performance and satisfaction will be expected to increase (Riemer, 2007). Although research findings have not consistently supported this hypothesis, issues concerning measurement of leaders’ actual behaviours and congruence are thought to have contributed to a lack of clarity (Riemer \& Toon, 2001).

Leadership preferences have most often been studied in sport by using the Leadership Scale for Sports (LSS; Chelladurai \& Saleh, 1980). The LSS measures five 
leadership behaviours: training and instruction (i.e. behaviours aimed at improving performance); democratic behaviour (i.e. participatory style); autocratic behaviour (i.e. personal authority); social support (i.e. focus on welfare of athletes); and positive feedback (i.e. use of praise or rewards). Research suggests that training and instruction, and positive feedback are the two most preferred behaviours of athletes, while autocratic behaviours are least preferred (cf. Chelladurai, 1993). According to Riemer (2007) athlete preferences for leadership behaviours are thought to be a function of an individual's characteristics (i.e. abilities, traits, needs).

Although Chelladurai $(1990,1993)$ has suggested greater attention is needed in relation to the influence of personality factors on leadership preferences of athletes, few researchers have investigated this aspect. However, Horn and Glenn (1988) found athletes with an internal locus of control showed preferences for coaches who exhibited more training and instructive behaviours. More recently, Horn (2008, p. 244), suggested 'we can no longer assume that one set of coaching behaviours will be effective for all athletes in all sports situations. Rather, we should recognise that effective coaching behaviours will vary as a function of the athlete and the sport context.' Given a lack of research concerning personality and leadership preferences, and suggestions that congruence between athlete preferences and actual coaching behaviours might influence both athletic performance and satisfaction (Chelladurai, 1990, 1993), it would seem appropriate to further examine how personality factors might relate to preferences for certain types of coaching behaviours. Attaining such knowledge could allow a coach to manipulate his or her coaching behaviours to attain congruence with athlete preferences. 
Mental toughness has recently emerged as an important psychological construct that is related to success in sport (cf. Crust, 2008). Clough, Earle and Sewell (2002) suggested mental toughness is a trait-like construct that allows individuals to remain relatively unaffected by competition or adversity. Mentally tough athletes are posited as having lower anxiety levels than others and an unshakeable faith that they control their own destiny (Clough et al., 2002). Clough et al. (2002) forwarded their own 4C’s model of mental toughness (Control, Commitment, Challenge, and Confidence) and a psychometric measurement instrument (MTQ48) based upon their definition and model. A recent behavioural-genetic study (Horsburgh, Schermer, Veselka, \& Vernon, 2009) of the relationships between mental toughness and personality has offered good support to the conceptualisation of mental toughness proposed by Clough et al. Furthermore, Horsburgh et al. reported exploratory and confirmatory factor analysis on the MTQ48 that supported the original six-factor structure of the measure (challenge, commitment, emotional control, life control, confidence in abilities and interpersonal confidence), and suggested that individual differences in mental toughness between adult twins were largely attributable to genetic and non-shared environmental factors.

In this study, we examined athletes’ preferences for leadership behaviours with respect to mental toughness. Given that mental toughness appears to reflect athletes with an internal locus of control, and previous work has showed an internal locus related to preferences for training and instructional behaviours (Horn \& Glenn, 1988), a positive relationship between mental toughness and preference for training and instructional behaviours was hypothesised. Since recent researchers have suggested that seeking social support may be incompatible with mental toughness (Nicholls, Polman, Levy \& 
Backhouse, 2008) a negative relationship between mental toughness and preference for social support was hypothesised.

Method

Participants

Participants were 103 athletes who all regularly participated in a variety of team sports (e.g., football, rugby, netball etc.) in the north of England. The sample consisted of 66 men $(M$ age $=22.58$ years, $S D=4.99)$ and 37 women $(M$ age $=21.11$ years, $S D=2.80)$. Of the participants, 36 were club / university athletes while the remaining 67 participants were competing at county standard. All participants completed an informed consent form prior to data collection. Ethical clearance for this research was achieved through the research ethics committee of York St. John University.

Instruments

The Leadership Scale for Sports (LSS; Chelladurai \& Saleh, 1978) was used to assess the leadership preferences of athletes. The LSS contains 40-items that are scored on a 5-point scale, with each item prefaced with the words 'I prefer my coach to...' This inventory contains five subscales that provide a comprehensive assessment of preferred coaching behaviours. Training and instruction (1) represents coaching behaviours aimed at improving performance through strenuous physical training, and includes emphasis on both technical and tactical components, as-well-as structuring and coordinating member activities. Democratic coaching behaviours (2) allow athletes to participate in decisionmaking processes, while in contrast autocratic behaviours (3) reflect independent 
decision-making and represent the coach as an authority figure. Coaching behaviours that demonstrate social support (4) are characterised by a concern for the welfare of athletes and are aimed at generating a positive group atmosphere. Finally, positive feedback (5) represents behaviours that reinforce an athlete by recognising and rewarding good performance (Chelladurai, 1990). The vast majority of research concerning athlete preferences for leadership behaviours has employed the LSS (Riemer, 2007). In general, the LSS has been found to have adequate psychometric properties, with the results of analyses supporting the validity and reliability of the measure (cf. Chelladurai, 1993; Chelladurai \& Riemer, 1998).

\section{Mental Toughness}

The MTQ48 (Clough et al., 2002), was used to measure mental toughness. This instrument was developed following qualitative work investigating elite athletes, coaches and sport psychologists’ perceptions and understanding of mental toughness in applied and theoretical contexts. Responses are made to the 48-items on a 5-point Likert scale ranging from (1) strongly disagree, to (5) strongly agree. The MTQ48 has an overall testretest coefficient of 0.9 , and previous studies have found high alpha coefficients for the MTQ48 (Nicholls et al., 2008). The psychometric development of the MTQ48 (cf. Earle, 2006) involved principal components analysis with varimax rotation. The most satisfactory solution was found to be a six-factor structure (challenge, commitment, emotional control, life control, confidence in abilities and interpersonal confidence). Challenge (1) describes the extent to which individuals view problems as opportunities for personal development, and thrive in changing environments. Commitment (2) reflects 
being deeply involved in what one is doing, and being able to persist despite obstacles or difficulties. Individuals who score high in emotional control (3) are able to keep their anxieties in check and are less likely to reveal their emotions to others. Life control (4) reflects a belief in personal influence as opposed to powerlessness. Individuals with high confidence in abilities (5) tend to be more optimistic and less dependent on external validation, while interpersonal confidence (6) reflects individuals who are more assertive and less likely to be intimidated in social settings. Clough et al. (2002) provided evidence for the construct validity of the MTQ48 with significant relationships reported with optimism ( $r=0.48)$, self-image ( $r=0.42)$, life satisfaction $(r=0.56)$, self-efficacy $(r=$ $0.68)$, and trait anxiety ( $r=0.57)$. In respect of criterion validity, the MTQ48 has been found to correlate with pain tolerance (Crust \& Clough, 2005) and a short-form version of the questionnaire has been shown to relate to injury rehabilitation (Levy, et al., 2006).

\section{Procedures}

Participants were solicited through advertisements at a number of local sports facilities where sports clubs and teams were known to regularly train. Brief information concerning the nature of the study was given in the advertisements along with requests for athletes who regularly competed in competitive sports and were over the age of 16 years, to complete two questionnaires. All participants were assured of confidentiality and informed of their right to withdraw consent. Questionnaires were completed individually and in isolation and were administered via the second named author who had experience in administering questionnaires. Completion of the questionnaires occurred in 
a variety of settings that were convenient, comfortable and non-threatening for respondents. Participants were not compensated for their involvement in the study.

\section{Data Analysis}

Data screening was used to ensure all dependent variables met the assumptions necessary for the use of parametric statistics prior to data analysis. Descriptive statistics (means, standard deviations) for all measures were also calculated. Pearson Product Moment Correlations were computed between all of the LSS factors, total mental toughness and the subscales of the MTQ48. Linear regression analysis (backward procedure) was used to determine the relationship between athletes' leadership preferences and mental toughness. Each subscale of the LSS acted as a dependent variable, with each of the six subscales of the MTQ48 acting as independent variables.

Results

Standard measures of skewness and kurtosis found the data to be normally distributed and as such use of parametric statistics was deemed appropriate. Descriptive data for responses to the MTQ48 and LSS questionnaires can be viewed in table 1. Results of the correlation analyses are presented in table 2. Only the training and instruction subscale of the LSS was found to significantly correlate with total mental toughness $(r=.40, P<$ 0.01). With the exception of interpersonal confidence, all other subscales of the MTQ48 were found to be significantly and positively related to a preference for training and instructive behaviours ( $r=.22$ to .36 ). The only other significant correlations found between subscales concerned the relationship between confidence in abilities and two 
subscales of the LSS (democratic behaviours and social support). In both cases significant and negative correlations were reported that represent athletes who were more confident in their abilities showing less preference for democratic behaviours $(r=-.27, P<0.01)$ and social support $(r=-.20, P<0.05)$ from coaches. Further to this it is worth reporting two other borderline significant correlations between the MTQ48 subscale of emotional control, and preferences for democratic behaviour ( $r=-.19, P=0.06)$, and social support $(r=-.19, P<0.06)$.

Results of the linear regression analyses can be viewed in table 3. A number of the MTQ48 subscales were found to significantly predict preferences for coaching behaviours, but only commitment and challenge were significant predictors of preference for training and instructive behaviours, accounting for approximately $18 \%$ of the variance in this variable. The $\mathrm{R}^{2}$ values reported, reflect that the independent variables (mental toughness subscales) accounted for between 6 and 18\% of the variance in preferences for coaching behaviours. Cohen and Cohen (1983) describe procedures for estimating effect size in regression analyses which involves the transformation of $\mathrm{R}^{2}$ values into an $f^{2}$ equation. By convention, $f^{2}$ values of $0.02,0.15$ and 0.35 are considered small, moderate and large effects in regression. According to the estimates provided by Cohen and Cohen, the amount of variance accounted for with respect to training and instructive behaviours (18\%) and democratic behaviours (14\%) is moderate. While significant $\mathrm{R}^{2}$ values were reported for autocratic, social support, and positive feedback behaviours, the amount of variance explained, and effect size is considered small.

Discussion 
This study examined the relationship between mental toughness and athletes’ preferred leadership behaviours. Consistent with theoretical predictions, a significant and positive relationship ( $r=0.40, P<.01$ ) was found between total mental toughness and a preference for training and instructive behaviours (i.e. skill development aimed at improving performance). This finding appears to be consistent with conceptualisations of mental toughness that emphasise an internal locus of control and a task oriented focus (Gucciardi, Gordon \& Dimmock, 2008; Jones, Hanton \& Connaughton, 2007). However, results from the regression analyses found that only the MTQ48 subscales of commitment and challenge were significant predictors of a preference for training and instructive behaviours. Previous research had identified a preference for training and instructive behaviours in athletes with an internal locus of control (Horn \& Glenn, 1988), and with a high need for information and structure in their environment (Chelladurai \& Carron, 1981). It is likely that mentally tough athletes' preference for training and instructive behaviours reflects a commitment to and striving for performance enhancement. Despite this finding, it is important to place such results into context, given that previous research has identified that in general, athletes prefer training and instructive coaching behaviours (Chelladurai, 1993). The present research suggests that a preference for training and instructive behaviours is even stronger in mentally tough athletes.

The direction of the relationship between total mental toughness and preference for social support was consistent with theoretical predictions although the correlation was not found to be significant $(r=-.12, \mathrm{p}>.05$ ). Results of the regression analysis did find that challenge, emotional control (negative weighting) and confidence in abilities (negative weighting) were significant predictors of preference for social support, although 
together, these subscales only accounted for approximately $8 \%$ of the variance in social support. Nicholls et al. (2008) had suggested that seeking social support was incompatible with mental toughness, although recent qualitative research has found social support to be important in the development of mental toughness (Connaughton, Wadey, Hanton \& Jones, 2008). The present results suggest that total mental toughness was not significantly related to a preference for social support, positive feedback, democratic or autocratic behaviours.

With regard to correlations between the subscales of the questionnaires, it was found that the MTQ48 subscale of confidence in abilities was significantly and negatively related to preferences for democratic behaviours and social support. Thus there is evidence that athletes who have high belief in their own abilities are less likely to prefer coaching behaviours that emphasise a participatory style and concern for athletes’ interpersonal needs and welfare. This appears to suggest such individuals are self-reliant, and may prefer a more task-focused, no-nonsense approach from leaders rather than the chance to participate in decision-making.

The linear regression analyses found that subscales of the MTQ48 were significant predictors of all five coaching behaviours measured by the LSS, although the amount of variance explained by predictor variables was small to moderate. Despite significant findings, drawing any firm conclusions should be avoided where $\mathrm{R}^{2}$ values are less than 0.1 (autocratic behaviours, social support behaviours and positive feedback behaviours), as less than $10 \%$ of the variance in dependent variables is accounted for in the independent variables. Interestingly, emotional control and life control were quite differently related to preference for democratic behaviours and positive feedback. 
Specifically, while emotional control negatively loaded against democratic behaviours and positive feedback, life control positively loaded against both variables. This finding appears to offer support to Clough et al. (2002) who found these aspects of control were related, but distinct factors.

The results for the total sample in this study (see table 1) are consistent with previous research (cf. Riemer, 2007) that has shown training and instructive behaviours and positive feedback to be the most preferred, and autocratic behaviours to be the least preferred leadership behaviours of athletes. Despite these results, the present study is limited in a number of ways and most obviously with regard to a relatively small sample size, the use of self-report inventories, and the correlational nature of the investigation. Furthermore, the present study used participants who were either club or county standard performers, and it is not known how these results would generalise to other populations such as national or international athletes. Further research is required not only concerning the leadership preferences of mentally tough athletes, but also considering the more general role of personality in such regards.

Given the purported benefits (performance and satisfaction) of attaining congruence between athlete preferences for coaching behaviours and actual coaching behaviours (Chelladurai, 1990, 1993), future research could attempt to test such predictions with respect to mental toughness. For example, it would be possible to test how the performances or satisfaction of more mentally tough athletes (as opposed to less mentally tough athletes) were influenced by incongruence between athlete preferences and coach behaviours. It might be predicted, based on the conceptualisation of mental toughness proposed by Clough et al. (2002), that mentally tough athletes would be less 
affected by incongruence given their ability to perform consistently regardless of situations or conditions.

Overall, the results of this study indicate that mentally tough athletes show preferences for leadership behaviours that are aimed at improving performance and skill development. This appears consistent with conceptualisations of mentally tough athletes as internally motivated, determined to succeed, focused on the task at hand with a high work ethic (Gucciardi et al., 2008; Jones et al., 2007). Other researchers have found mentally tough athletes to plan and prepare for competition meticulously (Bull et al., 2005: Jones et al., 2007) and such athletes would likely be seeking information to refine their performances. Athletes who were found to have high confidence in their abilities showed lower preferences for democratic behaviours or social support. Because of high self belief, these individuals are perhaps more likely to be able to cope with adversity and challenges without relying on others for support. The implication of this research for coaches working with mentally tough athletes is that to match athlete preferences (and potentially increase athlete satisfaction and performance), training and instructive behaviours should predominate.

\section{References}

Barrow, J. (1977). The variables of leadership: A review and conceptual framework. Academy of Management Review, 2, 231-251.

Bull, S., Shambrook, C., James, W., \& Brooks, J. (2005). Towards an understanding of mental toughness in elite English cricketers. Journal of Applied Sport Psychology, 17, 209-227. 
Chelladurai, P. (1978). A contingency model of leadership in athletics. Unpublished doctoral dissertation, University of Waterloo, Canada.

Chelladurai, P. (1990). Leadership in sports: A review. International Journal of Sport Psychology, 21, 328-354.

Chelladurai, P. (1993). Leadership. In R. N. Singer, M. Murphey, \& L. K. Tennant (Eds.), Handbook of research on sport psychology (pp. 647-671). New York: Macmillan. Chelladurai, P. (2001). Managing organization for sport and physical activity: A systems perspective. Scottsdale, AZ: Holcomb-Hathaway.

Chelladurai, P. \& Carron, A. (1981). Task characteristics and individual differences, and their relationship to preferred leadership in sports. In G. Roberts \& D. Landers (Eds.), Psychology of motor behavior and sport-1980 (p. 87). Champaign, IL: Human Kinetics.

Chelladurai, P., \& Riemer, H. A. (1998). Measurement of leadership in sport. In J. L. Duda (Ed.), Advances in sport and exercise psychology (pp. 227-253). Morgantown, WV: Fitness Information Technology.

Chelladurai, P., \& Saleh, S. (1978). Preferred leadership in sports. Canadian Journal of Applied Sport Sciences, 3, 85-92.

Chelladurai, P., \& Saleh, S. (1980). Dimensions of leader behavior in sports: Development of a leadership scale. Journal of Sport Psychology, 2, 34-45. Clough, P. J., Earle, K., \& Sewell, D. (2002) Mental toughness: the concept and its measurement. In I. Cockerill (Ed.), Solutions in Sport Psychology (pp. 32-43). London: Thomson. 
Cohen, J., \& Cohen, P. (1983). Applied multiple regression analysis for the behavioural sciences ( ${ }^{\text {nd }}$ ed.). Hillside, NJ. Erlbaum

Connaughton, D., Wadey, R., Hanton, S., \& Jones, G. (2008). The development and maintenance of mental toughness: Perceptions of elite performers. Journal of Sport Sciences, 26(1), 83-95.

Crust, L. (2008). A review and conceptual re-examination of mental toughness: Implications for future researchers. Personality and Individual Differences, 45(7), 576-583.

Crust, L. \& Clough, P. J. (2005). Relationship between mental toughness and physical endurance. Perceptual \& Motor Skills, 100, 192-194.

Earle, K. (2006). The construct of mental toughness: A psychometric and experimental analysis. Unpublished Ph.D. thesis. The University of Hull.

Gucciardi, D., Gordon, S., \& Dimmock, J. (2008). Towards and understanding of mental toughness in Australian football. Journal of Applied Sport Psychology, 20, 261281.

Horn, T. (2008). Coaching effectiveness in the sport domain. In T. Horn (Ed.), Advances in Sport Psychology, (3rd ed., pp. 239-267). Champaign, IL: Human Kinetics.

Horn, T., \& Glenn, S. (1988, June). The relationship between athletes’ psychological characteristics and their preference for particular coaching behaviours. Paper presented at the meeting of the North American Society for the Psychology of Sport and Physical Activity, Knoxville, TN. 
Horsburgh, V., Schermer, J., Veselka, L., \& Vernon, P. (2009). A behavioural genetic study of mental toughness and personality. Personality and Individual Differences, 46 (2), 100-105.

Jones, G., Hanton, S. \& Connaughton, D. (2007). A framework of mental toughness in the world's best performers. The Sport Psychologist, 21, 243-264.

Levy, A. R., Polman, R. C. J., Clough, P. J., Marchant, D. C., \& Earle, K. (2006). Mental toughness as a determinant of beliefs, pain, and adherence in sport injury rehabilitation. Journal of Sports Rehabilitation, 15, 246-254.

Nicholls, A. R., \& Polman, R. C., Levy, A. R., \& Backhouse, S. H. (2008). Mental toughness, optimism, and coping among athletes. Personality \& Individual Differences, 44, 1182-1192.

Riemer, H. (2007). Multidimensional Model of Coach Leadership. In S. Jowett \& D. Lavallee (Eds.), Social Psychology in Sport (pp. 57-73). Champaign, IL: Human Kinetics.

Riemer, H. \& Toon, K. (2001). Leadership and satisfaction in tennis: Examination of congruence, gender and ability. Research Quarterly for Exercise \& Sport, 72, 243-256. 
Table 1 - Means and standard deviations of MTQ48 and LSS

\begin{tabular}{lc}
\hline Dependent Variables & $(\mathrm{N}=103)$ \\
\hline MT Total & $176.14^{ \pm} 15.89$ \\
Challenge & $31.84^{ \pm} 4.19$ \\
Commitment & $40.91^{ \pm} 4.84$ \\
Emotional Control & $22.81^{ \pm} 3.42$ \\
Life Control & $25.56 \pm 3.60$ \\
Confidence Ability & $31.73 \pm 4.73$ \\
Confidence Interpersonal & $23.28 \pm 2.39$ \\
Training and Instruction & $4.11^{ \pm} 0.40$ \\
Democratic & $3.44^{ \pm} 0.46$ \\
Autocratic & $2.54 \pm 0.50$ \\
Social Support & $3.01 \pm 0.48$ \\
Positive Feedback & $4.39 \pm 0.46$ \\
\hline
\end{tabular}


Table 2 - Pearson correlations for the MTQ48 and the LSS

\begin{tabular}{|c|c|c|c|c|c|c|c|c|c|c|c|}
\hline & 1 & 2 & 3 & 4 & 5 & 6 & 7 & 8 & 9 & 10 & 11 \\
\hline \multicolumn{12}{|l|}{ 1. MT Total } \\
\hline 2. Challenge & $.74^{* *}$ & & & & & & & & & & \\
\hline 3. Commitment & $.69^{* *}$ & $.38^{* *}$ & & & & & & & & & \\
\hline 4. Emotional Control & $.69^{* *}$ & $.47^{* *}$ & $.31^{* *}$ & & & & & & & & \\
\hline 5. Life Control & $.71^{* *}$ & $.37 * *$ & $.40^{* *}$ & $.49^{* *}$ & & & & & & & \\
\hline 6. Confidence Abilities & $.74^{* *}$ & $.48^{* *}$ & $.35^{* *}$ & $.40^{* *}$ & $.39 * *$ & & & & & & \\
\hline 7. Conf. Interpersonal & $.43^{* *}$ & $.25^{* *}$ & .19 & .12 & $.26^{* *}$ & $.25^{* *}$ & & & & & \\
\hline 8. Training \& Instruction & $.40^{* *}$ & $.34^{* *}$ & $.36^{* *}$ & $.31^{* *}$ & $.26^{* *}$ & $.22 *$ & .07 & & & & \\
\hline 9. Democratic Behaviours & -.10 & -.05 & .05 & -.19 & .07 & $-.27 * *$ & .03 & -.01 & & & \\
\hline 10. Autocratic Behaviours & .07 & .17 & -.12 & .14 & .08 & .09 & -.11 & .05 & $-.24 *$ & & \\
\hline 11. Social Support & -.14 & .01 & -.05 & -.19 & -.06 & $-.20 *$ & -.07 & -.04 & $.43^{* *}$ & .13 & \\
\hline 12. Positive Feedback & .03 & -.05 & .11 & -.08 & .17 & -.06 & .01 & .17 & $.33^{* *}$ & .01 & .19 \\
\hline
\end{tabular}


Table 3 - Results of the linear regression analyses

\begin{tabular}{|c|c|c|c|}
\hline Dependent Variable & $\mathrm{R}^{2}$ & ANOVA & Variables Loading Significantly and Beta Value \\
\hline Training \& Instruction & 0.18 & 7.86; $\mathrm{P}<0.001$ & Commitment $\left(ß=.26^{* *}\right)$, Challenge $\left(ß=.24^{*}\right)$ \\
\hline Democratic & 0.14 & $5.16 ; \mathrm{P}<0.01$ & Emotional Control $\left(\beta=-.21^{*}\right)$, Confidence Ability $\left(ß=-.29^{* *}\right)$, Life Control $\left(\beta=.28^{* *}\right)$ \\
\hline Autocratic & 0.07 & $3.75 ; \mathrm{P}<0.05$ & Challenge $\left(\beta=.25^{*}\right)$, Commitment $(\beta=-.22 *)$ \\
\hline Social Support & 0.08 & 2.74; $\mathrm{P}<0.05$ & Challenge ( $(=.19 *)$, Emotional Control $(\beta=-.19 *)$, Confidence Ability $(ß=-.21 *)$ \\
\hline Positive Feedback & 0.06 & $3.27 ; \mathrm{P}<0.05$ & Emotional Control $\left(\beta=-.21^{*}\right)$, Life Control $\left(\beta=.27^{* *}\right)$ \\
\hline
\end{tabular}

$*=P<.05 ; * *=P<.01$ 